\title{
A PRAGMÁTICA TRANSCENDENTAL COMO "FILOSOFIA PRIMEIRA"
}

F. Javier Herrero*

Escolher ou aceitar para uma aula inaugural o tema da pragmática transcendental como "filosofia primeira" poderia parecer totalmente anacrônico. Anacrôni$\mathrm{Co}$, porque afinal vivemos no século XX, estamos acabando o século, e outros problemas parecem muito mais urgentes. Anacrônico sobretudo, porque quem hoje arriscaria tentar renovar na realidade atual a pretensão originariamente grega da filosofia como "filosofia primeira", quando isso significa levantar a pretensão de conhecer a totalidade ontológica do real em termos de razão e, portanto, de razão essencialmente metafísica? Afinal, será que a filosofia, com a maturidade de seus quase vinte e seis séculos de existência, não estaria sentindo a saudade de suas origens? Não teríamos então que decretar também a morte da filosofia como "filosofia primeira" e voltar-nos para a grande complexidade da vida moderna e tentar humildemente reduzi-la, porque isso já seria uma grande conquista? E afinal, não é esse o sentir comum de hoje quando por toda parte se proclama o advento da pós-modernidade que, entre outras coisas, se deleita na desconstrução de toda uma cultura metafísica e universalista?

Claro que numa primeira aproximação poderíamos ponderar que se a filosofia já conta na sua experiência com vinte e seis séculos de luta e de reflexão, é porque algo de muito importante ela teria descoberto e não seria finalmente por alguma moda que tudo isso deveria ser abandonado gratuitamente. Se é verdade que a pretensão de universalidade da filosofia sofreu os impactos do encontro com outras culturas que inevitavelmente tendem a questionar as prematuras universalizações, não por isso e automaticamente está em questão a mesma pretensão de universalidade. $\mathrm{E}$ se hoje a vida moderna diversificou e como que pulverizou a realidade em muitos setores cada um desenvolvendo sua racionalidade e seus critérios específicos, isso não só não torna supérflua a necessidade de uma reflexão sobre a totalidade, mas, ao contránio, ela se torna ainda mais urgente, porque se a filosofia provocou um questionamento radical da realidade como um todo e em verdade em termos de razão, isso deixou um legado de certo modo irreversivel:

* Universidade Federal de Minas Gerais - UFMG. 
o homem atual se vê confrontado, queira ou não, aceite-o ou não, com a exigência de dar um sentido à realidade como um todo e nenhum setor ou parcela de racionalidade poderá assumir essa tarefa. Antes, a multiplicação e diversificação de setores e de racionalidades existentes concorrem entre si pela primazia do sentido. E como a racionalidade que se impôs é a racionalidade técnico-científica, essencialmente manipuladora de seu objeto, por isso sumamente eficiente, surge com mais força que nunca a exigência de dar um sentido a tudo aquilo que o homem é capaz de fazer. E esse sentido terá que ser essencialmente humano.

Mas como consegui-lo? Apenas tentando redescobrir a Ética? De fato nunca se falou tanto em Ética como hoje, justamente porque a sua ausência provoca reações por toda parte, que mostram que a vida humana se autodestrói quando a Ética desaparece de seu horizonte. O ser humano e a sua liberdade perdem a sua dignidade e a sua razão de ser e de viver quando a Ética deixa de ser o marco constitutivo de sua convivência com os outros no mundo, quando a Ética não é mais a base e sustento de sua cidadania, quando a Ética desaparece da Política. Mas isso é suficiente?

Eis aqui que um autor contemporâneo chamado Karl-Otto Apel se propõe enfrentar os desafios da atualidade e, de certo modo, todos os desafios da atualidade, e para isso empreende a tentativa de reformular a pretensão universal da filosofia como "filosofia primeira", i. é, como filosofia teórica e prática em unidade, como filosofia capaz de dar razão de seu próprio discurso sobre a totalidade. Para poder realizar esta tarefa com alguma perspectiva de sucesso, terá que levar em conta as condições atuais das sociedades modernas, as conquistas da humanidade sobretudo neste século e as conquistas da mesma filosofia. O resultado é a elaboração de uma Pragmática transcendental como "filosofia primeira". Ela é construída tendo como marco uma Semiótica transcendental e por fundamentação uma reflexão estritamente transcendental sobre o discurso argumentativo. Nessa reflexão se mostrará que a razão, ao mesmo tempo teórica e prática, portanto, sendo já em si mesma ética, se fundamenta a si mesma, i. é, ela é consistente consigo mesma em todas as suas manifestações.

Tentarei expor com a brevidade de que disponho o essencial de cada passo da Pragmática transcendental. Mostrarei, em primeiro lugar, em que consiste a Semiótica transcendental, marco de toda a reflexão, para nele poder descobrir o cerne do que constitui o paradigma da nova versão de "filosofia primeira".

\section{1 - Semiótica transcendental}

Uma das grandes conquistas deste século foi a descoberta de que a linguagem mediatiza toda relação significativa entre sujeito e objeto e que ela está inevitavelmente presente em toda comunicação humana, a qual implica um "entendimento mútuo" sobre o sentido de todas as palavras usadas e sobre o sentido do ser das coisas mediadas pelos significados das palavras. Isso significa: a linguagem mediatiza todo sentido e toda validade.

E se a linguagem mediatiza todo sentido e toda validade, ela o faz, antes de mais nada, através dos sinais. Todo sentido é mediado pelos sinais lingüísticos. Por isso na base de todo sentido e de toda validade está, como já viu Peirce, a 
Semiótica (ciência dos sinais). Mas é necessário explicitar, em primeiro lugar, de que modo os sinais mediatizam todo e qualquer sentido.

É mérito de Peirce ter elaborado a tríplice função do sinal. Podemos exprimir essa tríplice relação na seguinte definição: um sinal é algo que representa algo diferente de si para os intérpretes. Explicitando isto podemos dizer que todo sinal implica: a) uma relação com a coisa representada, i. é, mediatiza algo do mundo; b) uma relação com o significado, i. é, mediatiza algo como algo significativo, que pertence a um sistema lingüístico; e c) uma relação com os seus intérpretes, i. é, mediatiza algo como algo significativo que tem que ser interpretado pelos membros de uma comunidade lingüística. Isso significa: já no uso dos sinais de uma língua está presente a dimensão pragmática da linguagem, i. é, a relação dos sinais com os sujeitos e com o uso que estes fazem dos sinais, e como tal ela integra as dimensões semântica e sintática.

A presença desta tríplice relação semiótica na constituição de todo sentido nos mostra já que o essencial em todo conhecimento é a interpretação de algo como algo, mediado pelos sinais. Isso significa: o conhecimento não pode ser reduzido nem aos meros dados dos sentidos como no positivismo clássico, nem à relação dual sujeito - objeto, como na filosofia moderna, nem a uma relação dual entre teorias e fatos no sentido da semântica (positivismo lógico), mas tampouco pode ser compreendido como uma pura mediação por conceitos no sentido da sintese transcendental da apercepção de Kant, porque em todos estes casos se prescinde da sintese hermenêutica da interpretação intersubjetiva do sentido dos sinais. Ora, a interpretação de algo como algo pressupõe sempre um nós que compreende e interpreta o sentido da proposição mediada pelos sinais lingüísticos. O conhecimento, a partir de sua mediação pela linguagem, só pode ser concebido como a compreensão comunicativa e formação do consenso sobre algo no mundo. I. é, essa compreensão intersubjetiva implica sempre um entendimento comum sobre os sinais usados, o qual possibilita todo ulterior entendimento ou desentendimento sobre algo do mundo. Assim na base de toda compreensão do significado e validade e, portanto, de todo conhecimento está sempre a estrutura do "entendimento sobre algo".

A partir daí podemos dizer: toda proposição da língua natural pressupõe, antes de mais nada, a identidade dos significados dos sinais lingǘsticos para todos os seres falantes de uma língua, os quais, com sua tríplice estrutura semiótica, remetem, por um lado, a um mundo da vida, e, por outro lado, a uma comunidade real de língua, na qual já existe um entendimento intersubjetivo sobre todos esses significados que nos possibilita a compreensão de um mundo compartilhado por todos. A linguagem mostra-se assim como condição de possibilidade de todo ulterior sentido e validade das proposições proferiveis através dos sinais lingüísticos. Nesse sentido a linguagem natural ou ordinária é, no seu uso atual, condição transcendental de possibilidade de todo sentido e validade. Não são então necessárias mais considerações para perceber que o significado dos sinais lingüísticos e das proposições que ele mediatiza é essencialmente público.

Em segundo lugar, essa mediação dos significados dos sinais lingüísticos é condição de possibilidade também do pensar, mesmo o realizado solitariamente, 
pois a) todo pensar só pode ter um conteúdo significativo porque ele é mediado pelos significados já constituídos da língua real e controlado pelas regras particulares dessa língua comunitária: Do contránio não se poderia pensar algo como algo significativo. Nenhuma consciência solipsista poderia extrair qualquer significado de algo sem esta mediação pública dos significados dos sinais; e b) todo pensar só pode reivindicar validade porque ele já tem uma estrutura discursiva, i. é, ele levanta a pretensão de poder defender o conteúdo pensado com boas razões diante de si mesmo e de todo possível contra-argumentante. Reivindicar validade significa pois levantar pretensões diante de uma comunidade, em princípio, ilimitada, que só podem ser satisfeitas por razões validas intersubjetivamente. $O$ pensar tem pois que ser entendido, na sua estrutura, como auto-entendimento argumentativo com pretensão intersubjetiva de validade. Por isso o pensador solitário terá que considerar, em princípio, no seu ato de pensar, no qual ele não pode enganar-se a si mesmo, as possíveis objeções de todos os possivieis parceiros do discurso. Assim a validade do seu discurso solitário exige e implica a justificação intersubjetiva de uma comunidade de argumentação, que ele interioriza num diálogo de si consigo mesmo, mas cuja validade é pública.

Em terceiro lugar, se toda proposição é mediada pelos sinais lingüísticos e pelos significados da língua natural, e isso significa que não se pode prescindir da dimensão pragmática da linguagem, então podemos e teremos que dizer que toda proposição semântica da língua natural é potencialmente pragmática, i. é, pode ser referida a um ato de fala que pode ser bem ou mal sucedido. Isso nos mostra que todo ato de fala tem uma dupla estrutura performativo-proposicional, i. é, um elemento performativo, pelo qual se estabelece um tipo determinado de comunicação e um elemento proposicional que constitui o conteúdo ou objeto da comuniçação, ou seja, toda proposição, pelo fato mesmo de ser proferida, implica uma atitude comunicativa, que nos relaciona com os outros, e uma atitude semânticoreferencial, que nos relaciona com algo do mundo. Por ex., na simples proposição: "chove", podemos explicitar o seu elemento performativo implícito na forma: "eu afirmo que chove". No ato performativo do afirmar está incluído o tipo de relação intersubjetiva que se pretende estabelecer com a proposição: "chove". Trata-se de uma comunicação orientada para as implicações do ato de afirmar. Essa dupla estrutura de todo ato de fala nos mostra que a comunicação visa essencial e originariamente ao entendimento mútuo nos dois níveis, no nível da intersubjetividade e no nível dos objetos de que se fala.

Esta dupla estrutura de todo ato de fala é de suma importância porque é por ela que podemos perceber os pressupostos pragmáticos implicados em toda proposição semântica. Asșim, por ex., as proposições semânticas não poderiam ser significativas se não houvesse em geral sujeitos humanos que pudessem compreendê-las e proferi-las; as proposições não poderiam ser em geral válidas ou inválidas se não pudéssemos e não tivéssemos que pressupor que há pretensões à validade, levantadas pelo conhecimento humano, que podem ser satisfeitas discursivamente ou não, e só por isso as proposições podem ser válidas ou inválidas; as proposições não poderịm ser verdadeiras ou falsas se não pudéssemos pressupor que há pretensões à verdade, levantadas pelo ato performativo das mesmas 
proposições; o predicado metalingüistico "é verdadeiro" não seria de modo algum compreensível se não pudéssemos pressupor que há pretensões auto-referenciais à verdade que podem ser explicitadas e questionadas nos discursos concretos, e por isso as proposições podem ser verdadeiras e falsas.

Com efeito, todo ato de fala levanta, implicitamente, pretensões à validade que enquanto pretensões se situam no elemento performativo. Assim com a proposição: "chove" levantamos, explicitamente, a pretensão à verdade, que enquanto pretensão necessária e universal, implícita no elemento performativo, poderá ser satisfeita ou não, e por isso toda proposição pode ser verdadeira ou falsa. Mas com ela é levantada, implicitamente, a pretensão à correção normativa relevante eticamente. Pois a pretensão à verdade, enquanto verdade, se refere à proposição, mas enquanto pretensão, é dirigida ao parceiro da comunicação e, enquanto tal, supõe implicitamente a pretensão à correção normativa dessa relação interpessoal pela qual o falante apela ao parceiro a proceder corretamente, i. é, a aceitar a pretensão à verdade ou a contestá-la unicamente com argumentos. Nesse caso $o$ falante se obriga igualmente a fundamentar a pretensão de sua afirmação com argumentos. Nesse sentido a resolução argumentativa da pretensão à verdade deverá pois ser também correta. $\mathrm{E}$ com a mesma pretensão à verdade, ainda é levantada, também implicitamente, a pretensão à veracidade ou sinceridade (também relevante eticamente). Pois a pretensão à verdade é também expressão do falante e, enquanto tal, se dirige ao parceiro da comunicação mas com a intenção de estar sendo sincero ao levantar a pretensão à verdade, i. é, ele levanta a pretensão para si mesmo de ser transparente na sua expressão e não visar outras intenções senão a da verdade. Com efeito, com afirmações verdadeiras podemos levar outros a enganos lamentáveis.

Assim toda pretensão, enquanto se refere à proposição, é pretensão à verdade; enquanto é dirigida ao parceiro da comunicação, é pretensão à correção normativa; e enquanto é expressão do mesmo falante, é pretensão à veracidade. Isso corresponde às três funções da linguagem implicadas em todo ato de fala. Este simultaneamente a) expressa uma intenção do falante, b) realiza uma relação interpessoal de apelo, e c) apresenta um estado de coisas do mundo. Nesse sentido, todo ato de fala visa entender-se com os outros sobre algo, através das pretensões levantadas.

Essa dupla estrutura performativo-proposicional possibilita, finalmente, a auto-reflexão na mesma linguagem que descobre através da explicitação do elemento performativo não só, como acabamos de ver, as pretensões de validade, mas na medida em que elas implicam os sujeitos humanos, descobrimos que nós temos que nos atribuir uma função transcendental, i. é, nós temos que saber-nos e julgar-nos capazes de levantar pretensões de validade e de tomar posição com respeito a elas, nós temos um saber reflexivo implícito de nossa relação com os outros e do que nós, nessa relação, podemos esperar dos outros. Nós, como sujeitos do conhecimento, temos que saber-nos e julgar-nos capazes de verdade, o que por sua vez significa que temos que pressupor-nos como instância crítica de reflexão sobre a validade. Nós, como sujeitos da ação, temos que saber-nos e julgarnos capazes de agir corretamente e de julgar as pretensões de correção, o que por 
sua vez significa que temos que pressupor-nos como seres autônomos na comunidade dos seres humanos. Enquanto tais, sabemos implicitamente que somos responsáveis, diante dos outros, pela veracidade de nossos propósitos, pela verdade de nossos enunciados e pela correção normativa de nossos juízos. Enfim, nós, como seres de linguagem, temos um saber reflexivo implícito de que em toda abertura lingüística do mundo se expressa essa relação intersubjetiva de comunicação e de que na descoberta de algo como algo se expressa o nosso "ser-nomundo" como compreensão do mundo e de nós mesmos. É através dessa relação intersubjetiva que se torna possivel a relação reflexiva do homem sobre si mesmo e a sua identificação como sujeito. E é essa dupla estrutura que nos permite, finalmente, captar a auto-reflexividade da mesma linguagem natural, i. é, que ela, ao mesmo tempo, mediatiza proposicionalmente todo sentido, sendo performativamente sua condição transcendental de possibilidade.

Tudo isso nos mostra que o logos da linguagem natural só pode ser adequadamente definido simultaneamente pelo significado performativo e pelo significado proposicional. É esta dupla estrutura que nos possibilita descobrir, por autoreflexão, a auto-referibilidade das condições de validade de todo ato de fala. A presença inevitável dessa dupla estrutura em toda fala e argumentação humanas nos mostra que entre os dois planos, o performativo e o proposicional, terá que haver sempre uma consistência, que pode ser designada como a consistência do logos humano.

Com estes breves traços de uma Semiótica transcendental, já podemos dizer que um novo paradigma é introduzido para toda reflexão filosófica em geral e em especial para a fundamentação a ética: o paradigma da linguagem que tem como base a tríplice relação dos sinais e como sustentação a comunidade ideal de comunicação ou, mais exatamente, um jogo lingüístico transcendental. Conseqüentemente, o novo paradigma se caracteriza antes de mais nada pela relação originária sujeito-sujeito. Isso significa: na base de toda concepção do conhecimento e de toda pretensão de validade se encontra originariamente, não a relação sujeitoobjeto, mas a estrutura intersubjetiva pragmático-transcendental do entendimento sobre algo. A partir deste novo paradigma, todo sentido, seja do pensar, seja do conhecer ou do agir, é mediado por uma comunidade real de língua e, na medida em que toda pretensão de sentido e de validade e pública, por uma comunidade ideal de comunicação e de argumentação. Todo sentido válido terá que ser concebido como algo que a priori é condicionado pela linguagem e, em conseqüência, terá que ser integrado na estrutura da comunicação, ou como veremos logo depois, na estrutura do discurso argumentativo.

\section{2 - O novo paradigma da "filosofia primeira"}

A partir dessa Semiótica transcendental da linguagem, que possibilita a dimensão hermenêutica do mundo e a tematização pragmático-reflexiva do humano ser-no-mundo, podemos agora mostrar em que consiste o novo paradigma da "filosofia primeira".

Começo com uma reflexão sobre o que Apel entende como "filosofia primeira”. A filosofia começou colocando a pergunta radical da razão: o que é o real, o 
que é o ser? Mas se, num primeiro momento, essa pergunta foi respondida em termos entitativos, com a realidade subsistente das idéias em Platão e com a ciência do ente enquanto ente em Aristóteles, que desembocou na exigência de um ente supremo que foi pensado como causa não contingente de todo ente, e posteriormente como causa sui e causa do mundo e mais tarde como Deus criador, essa resposta não foi satisfatória. Essa colocação provocou a célebre pergunta metafísica de Leibniz: "por que existe em geral algo em vez de nada"? Mas se, por um lado, essa pergunta é compreensivel em termos entitativos, a sua resposta levada até as suas últimas conseqüências implicaria no paradoxo de que tudo e nada foi explicado, pois cabe mais uma vez colocar a pergunta: "e por que existe Deus em lugar de nada"?

Isso significa: a resposta entitativa à pergunta radical da razão não dá ainda razão dos próprios pressupostos dessa colocação. A partir de onde se chega a essa resposta? A causalidade pressuposta não pode ser aplicada com sentido ao ente como um todo limitado, porque ela já pressupõe a distinção entre uma causa possivel determinada e o causado. Sabemos que Kant caracterizou como dogmática toda metafísica que não der razão de seus próprios pressupostos e limitou a pergunta do porque causal ao contingente, no sentido do mundo da experiência. Mas ele não abandonou sem mais a "filosofia primeira" explicando tudo como contingente. Antes, ele com a fundamentação da filosofia transcendental reconduziu a pergunta da "filosofia primeira" pelas causas do ente como um todo à pergunta pelas razões da validade de nossa representação objetual do ente contingente do mundo da experiência. Com isso nem tudo é contingente. A resposta de Kant levou à descoberta do sujeito transcendental como condição necessária de possibilidade da validade do nosso conhecer. Heidegger tentou colocar a pergunta pelo ser do ente e pelas condições de possibilidade do pensar como compreensão do ser, resultando na pergunta pelo Dasein ek-sistente como compreensão do ser. Não vou entrar aqui nas dificuldades desta colocação.

Apel vê nas diferentes colocações da "filosofia primeira" na história da filosofia uma seqüência no sentido de uma radicalização progressiva da reflexão sobre as condições de possibilidade do pensar válido. No primeiro paradigma, que com Heidegger pode ser caracterizado como "onto-teológico", o ser é reduzido à entidade e o sujeito racional como nous e logos é pensado como um ente intramundano. Dai a verdade, por exemplo, é pensada como adequação do entendimento com o ente. O problema da fundamentação última será problemático, pois fica difícil escapar de regresso até o infinito na série de causas. No segundo paradigma, o da "filosofia transcendental da consciência do objeto e de si", se coloca pela primeira vez a pergunta pelas condições de possibilidade de uma compreensão válida objetivamente. $\mathrm{O}$ problema da fundamentação da filosofia se resolve descobrindo 0 fundamento (agora não dogmático) como metodicamente intranscendível no pensar auto-reflexivo. O fundamento não será mais ôntico, mas transcendental. 0 problema maior deste paradigma é que, desconhecendo a mediação da linguagem e a compreensão intersubjetiva do mundo que ela possibilita, Kant vê ainda como exigência do pensar a prova da existência de um mundo externo, o que acabará levando a um mundo de fenômenos, distinto da coisa em si com tudo o que essa 
distinção implica para a razão teórica e para a razão prática, sobretudo para a fundamentação da ética, como a doutrina dos dois mundos.

A partir daí podemos ver já o que significa "filosofia primeira" para Apel. A pergunta radical da razão não pode ser tespondida em termos entitativos, sem que isso implique algum elemento dogmático na sua fundamentação. É essa dimensão entitativa que sempre se tornou objeto de crítica. Porém o que seria propriamente a dimensão ontológica remete ao ser, mas entendido como aquilo que em toda crítica tem que ser pressuposto como não ulteriormente transcendível, i. é, nãocontingente, mas como apriori necessário suposto em todo pensar válido. Este núcleo intranscendivel e, por isso, absolutamente incontestável é que constitui para Apel a "filosofia primeira". Assim a pergunta própria da "filosofia primeira" é: quais são as condições de possibilidade do pensar como compreensão do ser? ${ }^{\circ} \mathrm{Ou}$ o que seria o mesmo: quais são as condições de possibilidade do pensar válido?

$\mathrm{O}$ ponto arquimédico em que Apel se apoia para responder a essa pergunta é o discurso argumentativo. A argumentação ou o discurso argumentativo não é um jogo lingüístico entre outros no qual se possa entrar ou não à vontade, mas ele é tanto um tipo de comunicação quanto a "forma pública reflexivamente intransponivel do pensar". O discurso é um tipo de comunicação, porque também ele é mediado pelos sinais da linguagem, de forma que uma compreensão de algo como algo, também do argumentar como argumentar, é impensável sem a mediação da linguagem. Mas o discurso, mesmo o realizado por um sujeito solitário, é a forma pública reflexivamente intransponivel do pensar, porque ao argumentar com pretensões de validade, eu, na resolução dessas pretensões, já sou referido à comunidade em princípio ilimitada de argumentação, igualmente originária comigo. E é a forma reflexivamente intransponível do pensar, porque ele representa a instância última filosófica, científica e política na qual e diante da qual tem que justificar-se a responsabilidade comum dos homens pelo seu próprio pensar e pelo seu próprio agir, pelas suas teorias científicas e por toda fundamentação científica ou filosófica e, em geral, por todas as pretensões possiveis que possam ser levantadas no mundo da vida. Nenhuma fundamentação da ciência ou da ética, da semântica ou da pragmática, da racionalidade lógico-matemática ou de qualquer outra racionalidade, é possivel sem passar pela mediação do discurso e pelo discurso entendido em toda sua radicalidade. Neste sentido o discurso é metodicamente intranscendível.

E se o discurso é intranscendível e está necessariamente presente até no ato do pensar solitárị com pretensões de validade, então teremos que dizer kantianamente: as condições de possibilidade do discurso argumentativo sensato serão ao mesmo tempo as condições de possibilidade dos objetos de tal discurso. Nesta fórmula está recolhida a exigência da "filosofia primeira" de dar conta dos próprios pressupostos. Trata-se da consistência da dupla estrutura performativo-proposicional, que vimos antes, e que agora surge nos atos de fala argumentativos. Para a filosofia, isso significa: nenhuma corrente ou crítica filosófica poderá considerarse suficientemente legitimada, se na sua justificação não incluir as condições de possibilidade do próprio discurso. Apel chama isto o princípio da Selbsteinholung. 
E a fundamentação pragmático-transcendental da "filosofia primeira" ou o modo filosófico de dar conta dos pressupostos do próprio discurso só poderá acontecer por estrita auto-reflexão sobre o mesmo discurso, a única que nos possibilita explicitar, reconhecer e tomar consciência do que já sempre estávamos pressupondo implicitamente ao argumentar com sentido. Com efeito, se o discurso argumentativo está necessariamente presente até no ato solitário do pensar com pretensões de validade, então por estrita auto-reflexão comunicativa, e não por introspeção psicológica, eu poderei descobrir não só as condições de possibilidade do discurso, mas também que essas condições são transcendentais, i. é, intransponíveis e, portanto, necessárias, universais e últimas. A fundamentação última consistirá então no processo de auto-reflexão que me permite cerciorar-me de que essas condições são transcendentais, i. é, estão já sempre presentes em todo discurso, e de que, portanto, são elas que possibilitam a tematização de qualquer objeto do discurso. $\mathrm{E}$ a descoberta de que essas condições são transcendentais, me mostra que elas não poderão ser negadas sem cair em contradição performativa, porque elas estarão necessariamente presentes em qualquer tentativa de negálas como condição transcendental do sentido dessa negação. O qual supõe, por sua vez, que elas tampouco poderão ser provadas sem envolver petitio principii (círculo vicioso), porque toda prova já supõe, de novo, essas condições.

Isso significa: o processo de estrita auto-reflexão me mostra que se as condições transcendentais do discurso são as condições de possibilidade do objeto do discurso, então elas terão que ser co-afirmadas implicitamente na tematização desse objeto, i. é, o critério último de toda fundamentação será a consistência pragmática entre o objeto do discurso e as condições transcendentais de possibilidade do mesmo discurso, pressupostas necessariamente no ato performativo do mesmo discurso. Dito negativamente: o critério último de toda fundamentação pragmático-transcendental será a necessidade de se evitar a auto-contradição performativa.

Então partindo do fato de que o discurso argumentativo representa uma instância intransponível, e numa atitude estritamente auto-reflexiva, perguntamos: quais são as condições transcendentais de possibilidade da argumentação válida? Evidentemente aqui só poderei enunciar as condições mais importantes.

Todo discurso levanta, em primeiro lugar, as três pretensões universais à validade, que já vimos antes: à verdade, à correção e à veracidade. Basta acrescentar agora que a pretensão à verdade aparece explicitamente em primeiro plano nos atos de argumentação que se referem aos estados de coisas apresentáveis proposicionalmente no mundo objetivável; a pretensão à correção nos atos de argumentação que se referem ao agir e às interações no mundo social e a pretensão à veracidade nos atos de fala que se referem ao mundo subjetivo.

Em segundo lugar, e isto é de suma importância, a auto-reflexão sobre as pretensões à verdade e à correção nos mostra que elas são fundamentalmente, i. é, em princípio, não em cada caso particular, resolúveis de modo discursivo, i. é, por argumentos capazes, em princípio, de consenso, pois qualquer tentativa de mostrar o contrário já supõe essa discursividade. A pretensão à veracidade não 
poderá ser satisfeita por argumentos porque ela é condição de possibilidade da mesma discursividade argumentativa. Ela só é resolúvel na prática da vida.

Isso significa: a discursividade consensual e a condição transcendental de possibilidade da realização de todo pensar, conhecer e agir com pretensões de validade, pois

a) a resolução dessas pretensões só pode ser realizada discursivamente, i. é, por razões válidas intersubjetivamente e, por isso, em princípio, capazes de consenso;

b) e a resolução discursiva, na medida em que satisfaz pretensões diante dos outros, supõe a responsabilidade reciproca pela justificação da argumentação; e, portanto,

c) toda argumentação justificada discursiva e responsavelmente visa ao entendimento consensual, i. é, supõe uma racionalidade do entendimento ou racionalidade comunicativo-consensual.

Em terceiro lugar, a racionalidade do entendimento, na medida em que sempre implica uma relação intersubjetiva responsável, supõe a reciprocidade dialógica como estrutura universal de todo sentido e validade. E, por sua vez, a reciprocidade dialógica universal implica que todo sujeito argumentante é livre e autônomo para levantar pretensões de validade e para poder tomar posição sobre as pretensões levantadas pelos outros, e que todo sujeito argumentante tem igualdade de direitos na argumentação. Enquanto tais, todos somos co-responsáveis pelo reconhecimento da liberdade e dos direitos de todos, e pela solução discursivoconsensual de todos os problemas do mundo da vida. A ética está assim presente na racionalidade do entendimento.

Em quarto lugar, e mais fundamentalmente ainda, toda pretensão à validade $\mathrm{e}$ agora sem exceção, levanta também uma pretensão de sentido articulada lingüisticamente que se constitui por sua vez como condição de possibilidade das outras três pretensões de validade. Pois toda pretensão de validade pressupõe para a sua compreensão um sentido idêntico para todos das proposições. Mas esta pretensão de sentido supõe algo mais. Pois toda possivel resolução e crítica das pretensões à validade no discurso argumentativo não poderá ser ainda suficientemente compreendida sem outros pressupostos ontológicos do sentido. Com efeito, para que as três pretensões de validade já indicadas sejam compreensiveis, não basta pressupor, como parece aceitar Habermas, uma simples pretensão de sentido entendida como pretensão de compreensibilidade. Pois se deve haver uma relação interna entre a compreensibilidade de uma frase e o possivel cumprimento das outras três pretensões de validade, então não pode ser suficiente cumprir a condição sintática e semântica da boa formação da proposição. Se eu digo por ex.: "o atual rei da França é careca", essa proposição é sintática e semanticamente bem formada, portanto compreensivel, mas ela é sem sentido porque não pode ser verdadeira ou falsa com respeito a sua afirmação, uma vez que não preenche a pressuposição de existência, necessária para a sua possivel verdade: atualmente não existe um rei da Franca. O sentido dessa proposição exige pois uma pressuposição existencial, aqui no caso contingente. Quando Descartes diz: "talvez tudo o que vale como real é meramente um sonho", de novo, a proposição é compreensivel, mas ela é 
sem sentido porque não realiza a relação interna do predicado com as condições da verdade. Com efeito, o sentido do predicado: "é meramente um sonho" pressupõe que nem tudo o que vale como real é meramente um sonho. O predicado sonho supõe em princípio um mundo real, que possibilita a distinção com sentido de realidade e sonho. Só este pressuposto é que torna possível a dúvida sensata sobre esta ou aquela realidade concreta. Do contrário também a dúvida expressa na proposição "talvez tudo o que vale como real é meramente um sonho" poderia ser um sonho, e nem isso porque então também o termo sonho não teria um significado preciso. O sentido dessa proposição exige pois o pressuposto de um mundo real, aqui no caso um pressuposto ontológico.

Isso significa: às condições de possibilidade da compreensão das pretensões indicadas à verdade, à correção e à veracidade, que se referem respectivamente ao mundo objetivo, social e subjetivo, pertence a pretensão de validade do sentido. $\mathrm{E}$ as condições de possibilidade de sua resolução pertencem, em princípio, certas pressuposições ontológico-existenciais como a existência do eu argumentante, que tem que ser pensado como capaz de compreender e de argumentar, a existência dos outros, com os quais eu possa entender-me lingüisticamente sobre pretensões de validade, e a existência de um mundo real, que tem que ser pensado como significativo e compreensível e, por isso, como interpretável e cognoscível.

$\mathrm{E}$, finalmente, se o discurso levanta pretensões de sentido e de validade, resolúveis discursivamente, nós estamos pressupondo uma comunidade ideal de comunicação e argumentação, contrafaticamente antecipada, porque a pressuposição de que em princípio é possivel um consenso sobre todas as pretensões de validade, significa a antecipação da idéia regulativa de um entendimento intersubjetivo, ou consenso definitivo, i. é, não mais questionável, de uma comunidade ilimitada sobre as pretensões de validade, realizado nas condições lógicas e normativas ideais, que surge no horizonte como idéia a ser sempre visada e realizada. Do contrário, não teria sentido levantar pretensões e questionar a resolução discursiva das pretensões concretas levantadas no mundo da vida e nos discursos concretos. Mas nós sabemos igualmente que, se a comunidade ilimitada de comunicação e o consenso ideal sobre pretensões de validade são uma idéia regulativa, então nada empírico jamais poderá corresponder plenamente a ela, mas, ao contrário, ela nos mostra a tensão insuprimível, nos discursos teóricos, entre os consensos da verdade, possíveis de fato no tempo, e o consenso ideal, não mais questionável, e a tensão insuprimível, nos discursos práticos, entre as normas de fato validadas consensualmente no tempo pelos participantes dos discursos, e aquelas normas que seriam capazes de consenso para todos os possiveis afetados e para todos os possiveis julgadores de sua validade. E, portanto, junto com essa tensão, ela nos mostra a tarefa permanente e sempre inacabada de sua supressão a longo prazo.

E se todos esses pressupostos universais estão implicados na argumentação e, como tais, não podem ser negados sem cair em contradição performativa, então pelo simples fato de argumentar, nós já os temos reconhecido implicitamente. Do contrário a argumentação não teria sentido. Eles não surgem como conclusão 
dedutiva de alguma premissa da argumentação, mas como o incontestável, pressuposto e descoberto por estrita auto-reflexão sobre a mesma argumentação. Por isso, como critério de fundamentação última vale a seguinte fórmula:

\begin{abstract}
"como fundamentadas ultimamente podem valer aquelas pressuposições da argumentação que não podem ser contestadas sem auto-contradição performativa e, justamente por isso, não podem ser fundamentadas dedutivamente sem petitio principir".
\end{abstract}

Que razão está pressuposta nesta fundamentação última pragmático-transcendental? Antes de mais nada, trata-se de uma razão lingüística, porque também ela é mediada pelos sinais lingüísticos, de forma que uma compreensão de algo como algo, também da razão como razão, é impensável sem a mediação da linguagem. Mas como tal é uma razão comunicativa e não uma entidade ontológica ou uma faculdade mental, porque também ela tem que ser compreendida e interpretada pela comunidade de argumentantes. Ela é uma razão discursiva, cujo núcleo são as pretensões de sentido e de validade, teóricas e práticas, e que, sem prejuízo da autonomia teórica e da autonomia prática da consciência de cada pessoa singular, é referida a priori ao discurso ilimitado da comunidade de argumentação. É uma razão discursiva que, enquanto intersubjetiva, supõe a reciprocidade em todos os atos de entendimento, a norma do reconhecimento reciproco da liberdade e dos direitos de todos e, como tal, a co-responsabilidade de todos na solução de todos os problemas teóricos e práticos do mundo da vida. É, pois, uma razão, ao mesmo tempo, teórica e prática, já ética enquanto teórica. É uma razão que mostra a sua identidade, como sua razão de ser, na necessária concordância de si com todas as suas manifestações, no critério da consistência performativa (Kant falou da Selbsteinstimmigkeit der Vernunft), e que se dá a conhecer no critểio último da não-contradição performativa. O princípio de identidade da razão não é um princípio formal vazio, como o da identidade lógico formal $A=A$, porque ela é constituída, no seu conteúdo pragmático-transcendental, por todas as pressuposições existenciais e de regras, que 0 ato auto-reflexivo de argumentação discursiva tem que reivindicar performativamente. É por isso que o critério da consistência pragmática da razão consigo mesma em todas as suas manifestações funda o princípio da não-contradição lógica, próprio das proposições. É por isso que a racionalidade pressuposta por toda possivel teoria da racionalidade tem que ser a racionalidade do discurso, i. é, a da argumentação consistente, aquela que se deixa explicitar como autocertificação da identidade da razão argumentativa no teste da não-contradição performativa.

A razão que se mostra na fundamentação última pragmático-transcendental e, finalmente, 'uma razão transcendental, i. é, intransponivel, em todo ato humano sensato com pretensões de validade. É por isso que as perguntas: por que devo ser racional, por que devo agir moralmente, não são perguntas que devam ser respondidas por uma fundamentação dedutiva, que implicania um processo até o infinito e que, por isso, suporiam uma decisão prévia - não racional e não fundamentável - pela racionalidade. Antes, essas perguntas já estão respondidas por aquele que coloca sensatamente a questão. Porque quem coloca seriamente a pergunta, já entrou no discurso argumentativo e já aceitou e reconheceu, implicitamente, a razão e suas pressuposições normativas, lógicas e morais. E nenhum 
ser humano pode se recusar, em princípio, não em algum caso particular, a colocar essas questōes, porque isso implicaria em renunciar a pensar, uma vez que este já implica pretensões públicas de validade, só discursivamente resolúveis, e implicaria renunciar a agir, uma vez que este é incompreensivel sem a mediação dos sinais lingüísticos, válidos intersubjetivamente, e sem levantar pretensões de sentido como a pretensão à correção, implicaria, finalmente, na renúncia a uma identidade racional, já que estaria recusando não só o entendimento racional com os outros, mas também o entendimento consigo mesmo, necessariamente implicado em toda relação consigo mesmo, estaria, com outras palavras, se auto-destruindo.

- Isso significa: a pragmática transcendental decifra o que para Kant era um "fato da razão" como um "perfeito apriórico", i. é, como um ter já sempre reconhecido a razão e a lei moral, nela implicada, pelo discurso argumentativo, que reflexivamente descobre, inclui e assume suas condições normativas de possibilidade.

\section{Referências bibliográficas}

K.-O. APEL, "Der transzendentalhermeneutische Begriff der Sprache", em: Transformation der Philosophie, Bd. II, 330-357, Frankfurt, 1973 (trad. esp. em Taurus, Madrid, 1985).

—_ "Das Problem der philosophischen Letztbegründung im Lichte einer transzendentalen Sprachpragmatik, em: Sprache und Erkenntnis, (Hrsg. von B. Kanitscheider), 55-82, Innsbruck, 1976, (trad. esp. em: Estudios Filosóficos, 36 n 102 (1987) 251-299).

- "Transzendentale Semiotik und die Paradigmen der Prima Philosophia", em: Integrale Lingüistik, (Hrsg. von E. Bulow/P. Schmiter), 101-138, Amsterdam, 1979, (trad. fr. em: Revue de Métaphysique et de Morale, 98 (1993-4) 505-537.

— , "Die Logosauszeichnung der menschlichen Sprache" em: Perspektiven auf Sprache, (Hg. von H. G. Bosshardt, 45-87, Berlin, W. de Gruyter, 1986 (trad. fr. Le logos propre au langage humain, Ed. de l’Éclat, 1994).

geben?", em: Philosophie der Gegenwart - Gegenwart der Philosophie, (Hg. von Schnädelbach/G. Keil), Hamburg, 1993.

- "Das Selbsteinholungsprinzip der kritisch-rekonstruktiven Geisteswissenschaften" em: L'Art, la Science et la Métaphysique, (Hsg. von Academie Internationale de Philosophie de l'Art, Bem, P. Lange, 1993, 53-66.

- "Ist die transzendental-pragmatische Auffassung der Diskursrationalität eine Unterbestimmung der Vernunft?", em: P.Kolmer/H. Korten (Hrsg.), Grenzbestimmungen der Vernunft, Freiburg / München, Alber, 1994.

Rekonstruktion des Unterschiedes zwischen Verstand und Vernunft", em: Pragmatische Rationalitätstheorien, (Hrg. von A Wüstenhube), Würzburg, Königshause \& Neumann, 1995, 29-63.

- "Die Vernunftfunktion der kommunikativen Rationalität. Zum Verhältnis von konsensualkommunikativer Rationalitat, strategischer Rationalität und Systemrationalität", em: Die eine Vernunft und die vielen Rationalitäten (Hrg. von Apel / Kettner), Frankfurt, Suhrkamp, 1996. 